\title{
NEW LOCAL VIBRATIONAL MODES RELATED TO SILICON IN BULK AlGaAs*
}

\author{
P. KaCZoR, Z.R. ŻYTKIEWICZ AND L. DobaCZEWSKI \\ Institute of Physics, Polish Academy of Sciences \\ Al. Lotników 32/46, 02-668 Warszawa, Poland
}

\begin{abstract}
A silicon-related local vibrational mode absorption in AlGaAs is reported for the first time. It consists of six peaks grouped around $450 \mathrm{~cm}^{-1}$ which form a distinct pattern. We believe that the new local vibrational mode absorption is a fingerprint of a single defect. Among the discussed microscopic structures the most plausible is a $\mathrm{Si}_{\mathrm{G}_{a}}-\mathrm{Si}_{\mathrm{As}}$ pair complex with $\mathrm{Si}_{\mathrm{As}}$ acceptor interacting with different $\mathrm{Ga}, \mathrm{Al}$ nearest neighbour local environments.
\end{abstract}

PACS numbers: $61.72 . \mathrm{Vv}_{\mathrm{v}}, 63.20 . \mathrm{Pw}, 71.55 . \mathrm{Eq}$

A crucial factor limiting the sensitivity of local vibrational mode spectroscopy of ternary alloys is the sample thickness. With nonequilibrium growth techniques like MBE or MOCVD (metalorganic chemical vapour deposition) one is able to grow layers of up to $10 \mu \mathrm{m}$ only. In this case a high doping density is required leading inevitably to creation of complexes and precipitates. Our LPEE (liquid phase electroepitaxy) grown thick (up to $400 \mu \mathrm{m}$ ) AlGaAs samples with very high compositional uniformity $( \pm 1 \%)$ and relatively low doping levels $\left(5 \times 10^{17} \mathrm{~cm}^{-3}\right)$ are a worldwide unique high quality material for studying local vibrational mode absorption of isolated defects and simple complexes in ternary compounds.

In our experiment silicon, as a light impurity, has been introduced into the AlGaAs matrix. Although the Si impurity was thoroughly investigated in GaAs hy means of the LVM (local vibrational mode) technique (for review see e.g. [1]) there is little known about its behaviour in alloys. Additionally, $\mathrm{Si}$ is interesting from the point of view of its DX behaviour related to the localized vibrations. This problem is still under dispute [1]. In the alloy, the solution of this issue can be attempted without using highly sophisticated equipment needed for high pressure experiments [2].

Our $\mathrm{Al}_{x} \mathrm{Ga}_{1-x} \mathrm{As:Si}$ samples were grown by the liquid phase electroepitaxy method [3] with two different alloy compositions: $x=0.25$ (direct band-gap) and 0.43 (indirect band-gap). The doping levels and sample thicknesses were $1.5 \times 10^{18} \mathrm{~cm}^{-3}, 360-400 \mu \mathrm{m}$ and $5 \times 10^{17} \mathrm{~cm}^{-3}, 150 \mu \mathrm{m}$, respectively. The control

*This work has been supported by grants No. 2 P302 11705 and 223639023 of the State Committee for Scientific Research (Republic of Poland). 
samples doped with tellurium had approximately the same thickness and doping level. The absorption measurements were carried out with Bomem DA3 spectrometer equipped with a DTGS far-infrared detector in the range from 200 to 1000 $\mathrm{cm}^{-1}$. The resolution was $2 \mathrm{~cm}^{-1}$. During the measurement of the temperature dependence of the absorption two measurement regimes were applied: with and without germanium-filter at the light source. The Ge-filter cuts off the radiation above $0.68 \mathrm{eV}$ so the photoionization of the $\mathrm{DX}$ centre (threshold $=0.8 \mathrm{eV}$ ) cannot take place. When cooling the sample with near IR radiation cut off one can trap free carriers on DX centres obtaining a sample transparent in $200-1000 \mathrm{~cm}^{-1}$ range - perfectly suited for LVM measurements at low temperatures (where also the two-phonon absorption is the lowest).

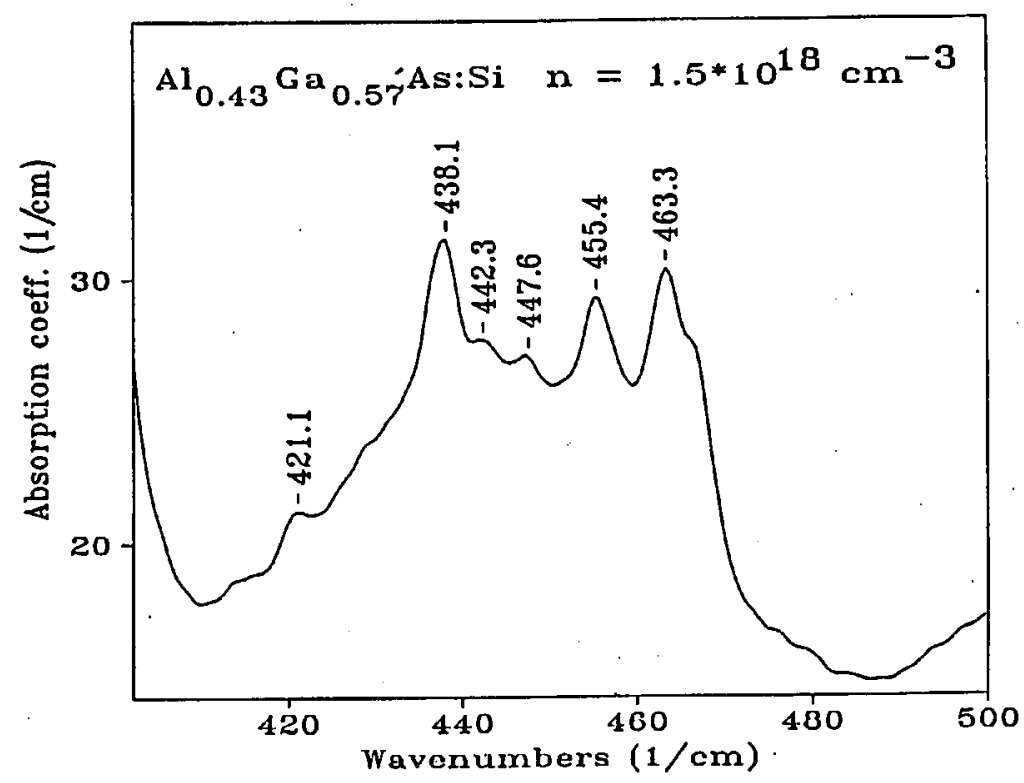

Fig. 1. Local vibrational modes of a Si defect in AlGaAs.

After cooling the sample down to approximately $230 \mathrm{~K}$ and below three sharp absorption peaks grouped around $450 \mathrm{~cm}^{-1}$ appear. Additionally, three other weaker lines can be seen when the signal-to-noise ratio is high enough (Fig. 1). The exact peak positions of these lines are summarized in Table.

Although the lines are superimposed on a two-phonon absorption band of AlGaAs lattice they cannot be attributed to the lattice modes for two reasons: (1) they are not present in Te-doped samples (Te-doping does not produce any LVM), and (2) they are stronger and their linewidth seems to decrease when the temperature is lowered while the lattice two-phonon absorption background decreases. Additionally, for the lower doping level, a decrease in peaks' strength can be observed. Ccasequently, one can conclude that the lines are the local vibrational modes of a defect containing silicon. 
Frequency positions of the LVM observed in $\mathrm{Al}_{x} \mathrm{Ga}_{1-x}$ As:Si with $x>0.25$.

\begin{tabular}{|c|c|c|}
\hline $\begin{array}{l}\text { Frequency of the peak } \\
\text { maximum }\left(\mathrm{cm}^{-1}\right)\end{array}$ & Strength & Identification \\
\hline 394.0 & strong & ${ }^{28} \mathrm{Si}_{\mathrm{Ga}}-{ }^{28} \mathrm{Si}_{\mathrm{As}}$ (transv.) \\
\hline 398.4 & strong & ${ }^{28} \mathrm{Si}_{\mathrm{AB}}$ \\
\hline 421.1 & weak & Si related $\left({ }^{30} \mathrm{Si}\right.$ isotope shift of the $438.1 \mathrm{~cm}^{-1}$ ?) \\
\hline 438.1 & strong & Si related $\left({ }^{28} \mathrm{Si}_{\mathrm{Ga}}-{ }^{28} \mathrm{Si}_{\mathrm{As}}+2 \mathrm{Al} \mathrm{NN}\right.$ ? \\
\hline 442.3 & weak & Si related $\left({ }^{30} \mathrm{Si}\right.$ isotope shift of the $455.5 \mathrm{~cm}^{-1}$ ?) \\
\hline 447.6 & weak & Si related $\left({ }^{30} \mathrm{Si}\right.$ isotope shift of the $463.3 \mathrm{~cm}^{-1}$ ?) \\
\hline 455.5 & strong & Si related $\left({ }^{28} \mathrm{Si}_{\mathrm{Ga}}-{ }^{28} \mathrm{Si}_{\mathrm{As}+1 \mathrm{Al} N \mathrm{NN}} ?\right)$ \\
\hline 463.3 & strong & Si related $\left({ }^{28} \mathrm{Si}_{\mathrm{Ga}}-{ }^{28} \mathrm{Si}_{\mathrm{As}+0 \mathrm{Al} \mathrm{NN}} ?\right)$ \\
\hline
\end{tabular}

The peak positions of the new LVM do not change with the alloy composition whereas for $x=0.25$ the relative intensity of the lowest frequency mode $\left(438 \mathrm{~cm}^{-1}\right)$ lowers with respect to the two higher frequency modes.

It was difficult to study the temperature dependence of the modes at temperatures higher than $250 \mathrm{~K}$ and lower than $90 \mathrm{~K}$ - due to high free carrier absorption background and/or shallow donor photoionization band making the measurement impossible for the higher doped samples. For the lower doped sample we could clearly observe a disappearing of the LVM at temperatures above $260 \mathrm{~K}$ and the same process when the sample was cooled down to 90-100 K (the shallow donor photoionization absorption was not too strong at these temperatures). Only when the Ge-filter was used the LVM could be observed down to $10 \mathrm{~K}$.

At the present stage it is possible to make some suggestions concerning a microscopic identification of the observed LVM pattern. The most plausible seems to be the $\mathrm{Si}_{\mathrm{Ga}}-\mathrm{Si}_{\mathrm{As}}$ donor-acceptor pair. Since in $\mathrm{GaAs}$ the $464 \mathrm{~cm}^{-1}$ peak corresponds to the longitudinal stretching mode of the pair [5] one can imagine that when $\mathrm{Al}$ atoms substitute $\mathrm{Ga}$ atoms nearest to the $\mathrm{Si}_{\mathrm{As}}$ cation sites the $\mathrm{Si}-\mathrm{Si}$ bond will become somewhat weaker due to an $\mathrm{Al}-\mathrm{Si}_{\mathrm{As}}$ bond strengliening. Then, depending on $\mathrm{Al}$ content, modes additional to the one at $464 \mathrm{~cm}^{-1}$ should appear at lower frequencies. From simple statistical calculations [6] it is clear that for $x=0.25$ the configurations with 0 and $1 \mathrm{Al}$ atoms (of total 4) will be dominant around $\mathrm{Si}_{\mathrm{As}}$, whereas at $x=0.43$ the configurations with more $\mathrm{Al}$ atoms are probable. Thus the peaks at $463.7,455$ and $457.5 \mathrm{~cm}^{-1}$ could roughly correspond to $0,1,2 \mathrm{Al}$ atoms around the $\mathrm{Si}_{\mathrm{As}}$ site. The observation of $399 \mathrm{~cm}^{-1}\left(\mathrm{Si}_{\mathrm{As}}\right)$ and $393 \mathrm{~cm}^{-1}\left(\mathrm{Si}_{\mathrm{Ga}}-\mathrm{Si}_{\mathrm{As}}\right.$ transverse) modes in the lowest doped sample is consistent with the above conclusion.

The above model assumes that the change of the lattice site of the $\mathrm{Si}_{\mathrm{Ga}}$ donor leading to DX centre formation plays a minor role (if any) when the donor-acceptor pair defect is considered. If the pair defect had contained the relaxed $\mathrm{Si}_{\mathrm{Ga}}$ the longitudinal Si-Si mode would shift to much lower frequencies (the highest frequency mode has almost the $464 \mathrm{~cm}^{-1}$ frequency of the isolated donor acceptor-pair mode). There seems to be no obvious reason for the $\mathrm{Si}-\mathrm{Si}$ bond strength to be 
large enough to prevent bond breaking in the case when the $\mathrm{Si}-\mathrm{As}$ bond breaking process is possible. Moreover, the difference between the temperature dependencies of the LVM absorption when measured with or without near-IR illumination is somewhat peculiar for the simple pair modes. The "dissolving" of the LVM into the lattice band at room temperature could have been explained with a strong anharmonic coupling but the same phenomenon at lower temperatures is difficult to understand.

There remains an opened question whether the DX-type bond configuration can be present in the defect observed. The LVMs appear and disappear when the DX centre is formed i.e. at $100-170 \mathrm{~K}$ with illumination and below $100 \mathrm{~K}$ with near-IR illumination cut off. For the reasons described above the observed LVMs could not be longitudinal modes of a $\mathrm{Si}_{\mathrm{Ga}}-\mathrm{Si}_{\mathrm{As}}$ pair but rather high frequency transverse modes. These modes would be either due to single donor DX configuration (due to three shortened $\mathrm{As}^{-} \mathrm{Si}_{\mathrm{Ga}}$ bonds) or a "broken pair". There would be only a minor difference between both types of configuration as the transverse modes originate primarily from the vibrations in the As-atoms plane.

\section{References}

[1] R.C. Newman, E.R. Webér, in series Imperfections in III/V Materials, Semiconductors and Semimetals, Vol. 38, Academic Press, London 1993, p. 118.

[2] J.A. Wolk, M.B. Kruger, J.N. Heyman, W. Walukiewicz, R. Jeanloz, E.E. Haller, Phys. Rev. Lett. 66, 776 (1991).

[3] Z.R. Żytkiewicz, S. Miotkowska, J. Cryst. Growth 121, 457 (1992).

[4] W.G. Spitzer, W. Allred, J. Appl. Phys. 19, 4999 (1968).

[6] T.N. Morgan, J. Electron. Mater. 20, 63 (1991). 